\title{
Perioperative management and outcomes of aortic surgery during pregnancy
}

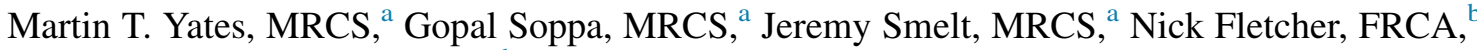 \\ Jean-Pierre van Besouw, FRCA, ${ }^{\mathrm{b}}$ Basky Thilaganathan, FRCOG, ${ }^{\mathrm{c}}$ and Marjan Jahangiri, FRCS(CTh) ${ }^{\mathrm{a}}$
}

Objective: Pathology of the aortic valve and ascending thoracic aorta is an uncommon but life-threatening complication of pregnancy. Cardiac surgery during pregnancy is known to carry a high risk of mortality to both the mother and fetus. We present our experience of performing aortic surgery during the patients' pregnancy.

Methods: All patients undergoing aortic surgery during pregnancy at St George's Hospital, from January 2004 until October 2013, were identified. Surgery was performed using cardiopulmonary bypass at $36^{\circ} \mathrm{C}$, with pulsatile perfusion at $70 \mathrm{~mm} \mathrm{Hg}$. Fetal blood flow parameters were serially monitored during surgery, via transabdominal and/or transvaginal Doppler ultrasonography. Surgery was performed in the second trimester when possible to allow completion of organogenesis and minimize hemodynamic compromise.

Results: Eleven patients underwent aortic surgery. The median age was 28 years (range, 26-31 years), with gestational age 19 weeks (range, 16-21 weeks). Six patients had aortic root dilatation with aortic regurgitation, and 5 had aortic stenosis, one of whom presented with acute type A dissection. Four patients had Marfan syndrome, and 2 had undergone previous cardiac surgery. The operative procedures were aortic root replacement (tissue valve, $\mathrm{n}=5$; homograft, $\mathrm{n}=1)$, aortic valve replacement $(\mathrm{n}=3)$, valve-sparing root replacement $(\mathrm{n}=1)$, and aortic and mitral valve replacements $(\mathrm{n}=1)$. Mean cardiopulmonary bypass and cross-clamp times were 105 and 89 minutes, respectively. There were no maternal deaths; 8 healthy babies were born at term, and 3 pregnancies resulted in intrauterine demise within 1 week of surgery.

Conclusions: Major aortic surgery during pregnancy carries a high risk to both mother and baby. With appropriate maternal and fetal monitoring, attention to cardiopulmonary bypass, pulsatile perfusion, near-normothermia, and avoidance of vasoconstrictors, these risks may be minimized. (J Thorac Cardiovasc Surg 2015;149:607-10)

See related commentary on pages 611-2.

Heart disease is present in only $1 \%$ to $2 \%$ of pregnant women; however, it accounts for $10 \%$ to $15 \%$ of all maternal deaths. ${ }^{1}$ Pathology of the aortic valve and the ascending thoracic aorta is an uncommon but life-threatening complication of pregnancy. Patients with known significant disease of their aortic valve or ascending thoracic aorta should be counseled before pregnancy regarding treatment of their condition. However, if patients are asymptomatic, with no family history of the disease, they may present with significant pathology or as an emergency during pregnancy. Patients can undergo cardiac

\footnotetext{
From the Departments of Cardiothoracic Surgery, ${ }^{\mathrm{a}}$ Anaesthetics, ${ }^{\mathrm{b}}$ and Foetal Medicine, ${ }^{\mathrm{c}}$ St George's Hospital, London, United Kingdom.

Disclosures: Authors have nothing to disclose with regard to commercial support. Received for publication June 25, 2014; revisions received Sept 24, 2014; accepted for publication Oct 4, 2014; available ahead of print Dec 15, 2014.

Address for reprints: Marjan Jahangiri, FRCS(CTh), Department of Cardiac Surgery,

St George's Hospital, Blackshaw Rd, London, SW17 0QT, United Kingdom

(E-mail: marjan.jahangiri@stgeorges.nhs.uk).

$0022-5223 / \$ 36.00$

Copyright (C) 2015 by The American Association for Thoracic Surgery

http://dx.doi.org/10.1016/j.jtcvs.2014.10.038
}

surgery during pregnancy, but it is known to carry a high risk of mortality for both the mother and fetus. ${ }^{2}$

The literature on cardiac surgery during pregnancy is dominated by reports on patients who have undergone mitral valve repair or replacement, without specific attention to the details of cardiopulmonary bypass $(\mathrm{CPB}){ }^{3}$ A few reports have discussed surgery on the aortic valve and thoracic aorta during pregnancy. ${ }^{4}$ Therefore, data are limited regarding the outcomes of aortic surgery in pregnancy, as is knowledge about optimal perioperative management. We have previously presented our initial case series and conduct of CPB. ${ }^{4}$ The aim of the current paper is to describe our management of aortic surgery during pregnancy and present the results of our current series with specific attention to $\mathrm{CPB}$ and fetal monitoring.

\section{PATIENTS AND METHODS \\ Patients}

All patients who underwent aortic and aortic valve surgery during pregnancy at St George's Hospital, from January 2004 until October 2013, were identified from a prospectively collected database. Patient demographics and operative details were recorded. All patients were followed up locally. Surgery was performed in the second trimester when possible. Patients presenting early in pregnancy were 


\section{Abbreviation and Acronym \\ $\mathrm{CPB}=$ cardiopulmonary bypass}

managed conservatively until the second trimester, if possible, to allow completion of organogenesis. Completion to full-term pregnancy before surgery was prevented, to reduce the risk of rupture or heart failure during delivery. Permission was obtained for publication of this series.

\section{Maternal and Fetal Monitoring}

Maternal uteroplacental perfusion was monitored by measuring Doppler indices in both uterine arteries. ${ }^{5}$ Fetal monitoring consisted of serial assessments of Doppler indices in the umbilical and middle cerebral arteries using transabdominal Doppler ultrasound. ${ }^{6}$ The transvaginal route was utilized when the surgical field precluded the use of the transabdominal approach.

\section{Surgical Technique}

An opiate-based, balanced anesthetic technique, with propofol and muscle relaxation, is used for all patients. Cerebral oximetry monitoring is established pre-induction, and anesthetic doses are carefully titrated to maintain adequate invasive arterial pressure and cerebral oxygen saturation. Standard maternal monitoring for adult cardiac surgery was used in all patients. Patients were positioned supine in the lithotomy position to allow surgical access to the chest and concomitant transvaginal scanning. Because patients were in a relatively early stage of pregnancy, we did not use special measures to prevent aortocaval compression. All procedures were performed via median sternotomy.

\section{Cardiopulmonary Bypass}

CPB was established using central aortic and right atrial cannulation at $36^{\circ} \mathrm{C}$, with pulsatile perfusion. CPB is established using a Stockert S5 modular heart-lung machine (Sorin Group, Milan, Italy). Pulse mode is enabled with initial pulse parameters set as follows: pulse frequency, 60/min; pulse width, 30\%; and base flow, $30 \%$. Standard CPB flow rate is $2.4 \mathrm{~L} / \mathrm{min} / \mathrm{m}^{2}$ body surface area. The flow rate is increased by $20 \%$ in pregnant patients. Hemoglobin is maintained above $9 \mathrm{~g} / \mathrm{dL}$ during the perioperative period. In the patient with aortic dissection, central aortic cannulation was achieved using periaortic ultrasound and tranesophageal echocardiography. Strict avoidance of vasoconstrictors and blood products was maintained when possible, to avoid feto-placental vasoconstriction. $\mathrm{CPB}$ and cross-clamp times were kept to a minimum. Circulatory arrest was avoided in all cases.

\section{Follow-up}

All patients were reviewed at 6 weeks after discharge and, in addition, were seen as required by the obstetric team. Fetal assessment was repeated at 2 to 4 weeks postsurgery to assess uteroplacental function by Doppler ultrasound and exclude the development of fetal brain abnormalities as a consequence of prolonged intraoperative fetal hypoxemia.

\section{Statistics}

Data are presented as median with interquartile range, unless stated otherwise.

\section{RESULTS}

During the study period, 11 patients underwent surgery during pregnancy. Median age was 28 years (range, 26-31 years) with a gestational age of 19 weeks (range, 16-21 weeks). Four patients had Marfan syndrome, and 2 had undergone previous cardiac surgery. Patient characteristics and diagnosis are shown in Table 1. Six patients had aortic root dilatation with aortic regurgitation, and 5 had aortic stenosis. Those with stenosis presented in congestive cardiac failure. The operative procedures were aortic root replacement (tissue valve, $\mathrm{n}=5$; homograft, $\mathrm{n}=1)$, aortic valve replacement $(\mathrm{n}=3)$, valve-sparing root replacement $(\mathrm{n}=1)$, and aortic and mitral valve replacements $(\mathrm{n}=1)$, as shown in Table 1. Mean $\mathrm{CPB}$ and cross-clamp times were 105 and 89 minutes, respectively.

Figure 1 demonstrates typical fetal hemodynamics throughout the perioperative period, comparing maternal mean arterial pressure to fetal heart rate and the uterine artery pulsatility index. At induction of anesthesia (point A), despite maintenance of maternal mean arterial pressure and fetal heart rate, the pulsatility index fell. Once CPB was established (point $B$ ), the hemodynamics were maintained. The mother was weaned from bypass at point $C$. The importance of multimodality fetal monitoring is highlighted by episodes of reduced fetal perfusion, despite normal fetal heart rate. This reduction in perfusion would not be apparent if only fetal heart rate were measured.

There were no strokes, and no resternotomy for bleeding. We aim to maintain an $\mathrm{Hb}$ of $9.0 \mathrm{~g} / \mathrm{dL}$, and 4 patients required transfusion of 2 units of red-cell concentrate. There were no maternal deaths, and all patients were discharged to their homes, well, at 7 days (range, 7-9 days); there were no intraoperative fetal deaths. However, 3 fetuses died within 1 week after surgery; all had features of hydrops. One of the deaths was concurrent with administration of $\beta$-blocker, associated with irreversible fetal bradycardia. Eight babies were born at term. At a mean follow-up of 4.2 years, all mothers and babies were well.

\section{DISCUSSION}

Our series includes only those patients who had no option to deliver their baby before surgery, owing to the urgency of the need for surgery and the low likelihood of survival of the fetus with premature delivery. The maternal mortality for cardiac surgery during pregnancy has been reported to be $2 \%$ to $14 \%{ }^{2}$. Fetal mortality ranges from $15 \%$ to $30 \%{ }^{2}$ A recent study by Elassy and colleagues ${ }^{8}$ reported 12 patients who required either aortic and/or mitral valve surgery during pregnancy. There were 10 intrauterine deaths in those undergoing surgery. Overall maternal mortality in the latter series was $8.7 \%$. John and colleagues ${ }^{9}$ presented 21 patients undergoing cardiac surgery during pregnancy. Of these, 8 underwent aortic valve replacements, and 2 underwent aortic aneurysm repairs. Two fetal deaths occurred in this group, one during aortic valve replacement and the other during aneurysm repair. There were no maternal deaths. 
TABLE 1. Demographics of patients undergoing aortic surgery during pregnancy using pulsatile, normothermic CPB

\begin{tabular}{|c|c|c|c|c|c|}
\hline $\begin{array}{c}\text { Maternal } \\
\text { age (years) }\end{array}$ & $\begin{array}{c}\begin{array}{c}\text { Gestation at } \\
\text { time of surgery } \\
\text { (weeks) }\end{array} \\
\end{array}$ & Diagnosis & Type of surgery & $\begin{array}{c}\text { Gestation at } \\
\text { delivery } \\
\text { (week of } 40 \text { ) }\end{array}$ & $\begin{array}{c}\text { Fetal } \\
\text { outcome } \\
\end{array}$ \\
\hline 31 & 11 & Aortic regurgitation, root $6.9 \mathrm{~cm}$, Marfan & Aortic root replacement (porcine) & 38 & Well \\
\hline 38 & 15 & Aortic stenosis + mitral stenosis & $\begin{array}{l}\text { Aortic valve replacement }+ \text { mitral valve } \\
\text { replacement (porcine) }\end{array}$ & 16 & Died \\
\hline 24 & 16 & Aortic stensosis, previous AVR & Redo homograft root replacement & 38 & Well \\
\hline 29 & 18 & Aortic regurgitation, root $5.9 \mathrm{~cm}$, Marfan & Aortic root replacement (bovine) & 19 & Died \\
\hline 26 & 19 & Aortic stenosis, previous open valvotomy & Redo aortic valve replacement (porcine) & 38 & Well \\
\hline 24 & 19 & Aortic stenosis & Aortic valve replacement (porcine) & 38 & Well \\
\hline 27 & 19 & Aortic regurgitation, root $6.7 \mathrm{~cm}$, Marfan & Aortic root replacement (bovine) & 38 & Well \\
\hline 31 & 20 & Aortic stenosis & Aortic valve replacement (porcine) & 21 & Died \\
\hline 28 & 21 & Aortic dissection, asc aorta $4.5 \mathrm{~cm}$ & Aortic root replacement (porcine) & 38 & Well \\
\hline 29 & 21 & Aortic regurgitation, root $6.4 \mathrm{~cm}$ & Valve-preserving aortic root replacement & 38 & Well \\
\hline 28 & 24 & Aortic regurgitation, root $7.2 \mathrm{~cm}$, Marfan & Aortic root replacement (porcine) & 37 & Well \\
\hline
\end{tabular}

AVR, Aortic valve surgery; asc, ascending.

Pregnancy results in significant hemodynamic changes, to meet the increased metabolic needs of the mother and fetus. Cardiac output is increased by up to $50 \%$, resulting from an increase in the circulating volume and heart rate. ${ }^{10}$ These changes are compensated for by a reduction in systemic vascular resistance. In addition, hypercoagulability occurs, owing to increased fibrinogen and platelet adhesiveness. In patients with underlying cardiac pathology, such as aortic stenosis, these alterations can result in acute cardiac failure that requires urgent valve replacement. In those with a predisposition to aortic aneurysm, the hemodynamic changes, in addition to hormonal alteration increasing the elasticity of the aortic wall, increase the chance of dilatation of the aorta or acute dissection.

The natural history of aortic aneurysms has been well documented. It is known that the larger the aortic diameter, the greater the growth rate and chance of rupture or dissection. ${ }^{11}$ During the course of a normal pregnancy, the aortic diameter increases a small amount. This increase is significantly larger in the presence of hypertension, with

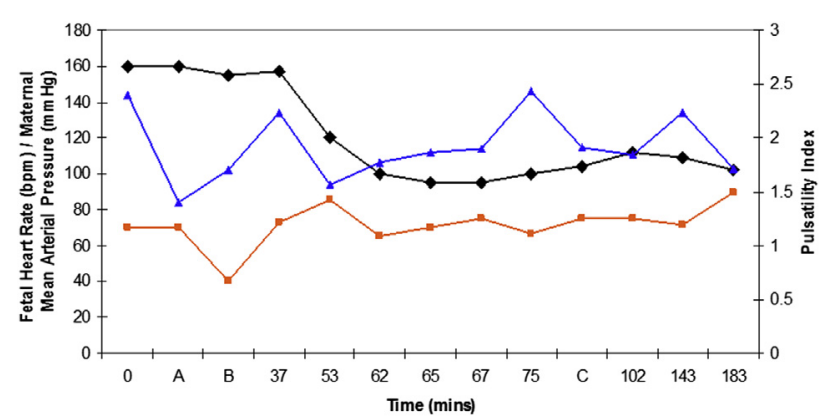

FIGURE 1. Typical fetal hemodynamics throughout the perioperative period, comparing maternal mean arterial pressure (red line) with fetal heart rate (black line) and uterine artery pulsatility index (blue line). bpm, Beats per minute. the maximal diameter occurring in the final few weeks of pregnancy. ${ }^{12}$ In patients with Marfan Syndrome, the aorta was found to grow more rapidly during pregnancy, compared with the growth in an age-matched cohort. ${ }^{13}$ Furthermore, pregnancy increased the likelihood of adverse outcomes and longer-term need for aortic surgery. ${ }^{13}$ Therefore, the threshold for intervention on the ascending aorta in pregnancy must be lower, and such patients should not be allowed to go to full-term pregnancy, because of the increased risk of rupture.

The challenges of cardiac surgery during pregnancy vary with the stage of pregnancy. In the first trimester, there is a significant risk of congenital anomalies. In the third trimester, hemodynamic changes in the mother create significant risks of hemodynamic collapse to both the mother and fetus, while establishing and weaning from CPB. The second trimester is thought to be the safest time to carry out cardiac surgery, as the main organogenesis of the fetus has been completed but the large hemodynamic changes in the mother's circulation are not fully established.

$\mathrm{CPB}$ has multiple effects on the pregnant uterus, as a result of changes in pressure, flow, and temperature. Fetal death is most commonly noted during the cooling and rewarming phases of bypass, which can be avoided with near-normothermic bypass. Fetal outcomes in a series comprising both hypothermic and normothermic bypass have been shown to be significantly worse in the hypothermia group. ${ }^{14}$ Hypothermic circulatory arrest almost invariably results in fetal demise ${ }^{15,16}$ and therefore should be avoided; on the other hand, success has been reported in isolated cases. ${ }^{17}$

The normal uterine vasculature in early pregnancy requires high-pressure, pulsatile flow patterns to achieve good uteroplacental perfusion. Low-flow, nonpulsatile perfusion causes hypoxia in the uterus, initiating 
contractions. We therefore use pulsatile perfusion while maintaining high pressure and flow throughout. In an experimental model, placental blood flow was significantly increased with pulsatile perfusion. ${ }^{18}$ This increase was partly due to the release of nitric oxide, an arterial vasodilator, which has been shown to be at significantly higher levels during pulsatile perfusion. ${ }^{19}$ In addition, the same model showed significantly less activation of the renin-angiotensin system, which may contribute to higher placental blood flow. We avoid the routine use of vasoconstrictors unless they are absolutely necessary.

In addition to full invasive monitoring of the mother, in this series, we used continuous, serial, fetal monitoring via Doppler ultrasonography, ${ }^{10}$ which allows real-time assessment of blood flow in the umbilical and middle cerebral arteries. An increase in umbilical artery resistance, and a decrease in middle cerebral artery resistance, are typical of the changes seen with fetal hypoxemia. ${ }^{20}$ These changes reflect the so-called brain-sparing effect of fetal arterial redistribution, which is seen as an attempt to maintain fetal brain oxygenation under hypoxemic conditions. Such monitoring allows optimal control of $\mathrm{CPB}$, to maintain adequate fetal oxygenation intraoperatively. If fetal distress occurs, it prompts us to review all parameters to ensure that they are optimal. Despite optimum parameters, signs of ongoing fetal distress may lead to further measures. In the case of fetal bradycardia, we may give atropine. However, the safety of the mother is always the priority.

In conclusion, aortic surgery during pregnancy carries a high risk to both mother and baby. With full maternal and fetal monitoring, and attention to cardiopulmonary bypass, pulsatile perfusion, near-normothermia, and avoidance of vasoconstrictors, risks may be minimized.

\section{References}

1. Regitz-Zagrosek V, Lundqvist CB, Borghi C, Cifkova R, Ferreira R, Foidart J-M, et al. ESC guidelines on the management of cardiovascular diseases during pregnancy. Eur Heart J. 2011;32:3147-97.

2. Kapoor MC. Cardiopulmonary bypass in pregnancy. Ann Card Anesth. 2014;17: 33-9.
3. Parry AJ, Westaby S. Cardiopulmonary bypass in pregnancy. Ann Thorac Surg. 1996;61:258-69.

4. Jahangiri M, Clarke J, Prefumo F, Pumphrey C, Ward D. Cardiac surgery during pregnancy: pulsatile or non-pulsatile perfusion? J Thorac Cardiovasc Surg. 2003; 126:894-5.

5. Velauthar L, Plana MN, Kalidindi M, Zamora J, Thilaganathan B, Illanes SE, et al. First-trimester uterine artery Doppler and adverse pregnancy outcomes: a meta-analysis of 55,974 women. Ultrasound Obstet Gynecol. 2014;43:500-7.

6. Lees C, Marlow N, Arabin M, Bilardo CM, Brezinka C, Derks JB, et al. Perinatal morbidity and mortality in early-onset fetal growth restriction: cohort outcomes of the trial of randomized umbilical and foetal flow in Europe (TRUFFLE). Ultrasound Obstet Gynecol. 2013;42:400-8.

7. Khalil A, Suff N, Thilaganathan B, Hurrell A, Cooper D, Carvalho JS. Brain abnormalities and neurodevelopmental delay in congenital heart disease: systematic review and meta-analysis. Ultrasound Obstet Gynecol. 2014;43: $14-24$.

8. Elassy SMR, Elmidany AA, Elbawab HY. Urgent cardiac surgery during pregnancy: a continuous challenge. Ann Thorac Surg. 2014;97:1624-9.

9. John AS, Gurley F, Schaff HV, Warnes CA, Phillips SD, Arendt KW, et al. Cardiopulmonary bypass during pregnancy. Ann Thorac Surg. 2011;91: 1191-7.

10. Mishra M, Sawhey R, Kumar A, Bapna KR, Kohli V, Wasir H, et al. Cardiac surgery during pregnancy: continuous fetal monitoring using umbilical vein Doppler flow velocity indices. Ann Card Anesth. 2014;17:46-51.

11. Davies RR, Goldstein LJ, Coady MA, Tittle SL, Rizzo JA, Kopf GS, et al. Yearly rupture or dissection rates for thoracic aortic aneurysms: simple prediction based on size. Ann Thorac Surg. 2002;73:17-28.

12. Easterling TR, Benedetti TJ, Schmucker BC, Carlson K, Millard ST. Maternal hemodynamics and aortic diameter in normal and hypertensive pregnancies. Obstet Gynecol. 1991;78:1073-9.

13. Donnelly RT, Pinto NM, Kocolas I, Yetman AT. The immediate and long-term impact of pregnancy on aortic growth rate and mortality in women with Marfan syndrome. J Am Coll Cardiol. 2012;60:224-9.

14. Pomini F, Mercogliano D, Cavalletti C, Caruso A, Pomini P. Cardiopulmonary bypass in pregnancy. Ann Thorac Surg. 1996;61:259-68.

15. Sakaguchi M, Kitahara H, Seto T, Furusawa T, Fukui D, Yanagiya N, et al. Surgery for acute Type A aortic dissection in pregnant patients with Marfan syndrome. Eur J Cardiothorac Surg. 2005;28:280-3.

16. Wakiyama H, Nasu M, Fujiwara H, Kitamura A, Okada Y. Two surgical cases of acute aortic dissection in pregnancy with Marfan syndrome. Asian Cardiovasc Thorac Ann. 2007;15:63-5.

17. Kunushige H, Ishibashi Y, Kawasaki M, Yamakawa T, Morimoto K, Inoue N. Surgical treatment for acute type A aortic dissection during pregnancy (16 weeks) with Loeys-Dietz syndrome. Gen Thorac Cardiovasc Surg. 2012; 60:764-7.

18. Champsaur G, Parisot P, Martinot S, Ninet J, Robin J, Ovize M, et al. Pulsatility improves hemodynamics during fetal bypass. Experimental comparative study of pulsatile versus steady flow. Circulation. 1994;90:47-50.

19. Vedrine C, Tronc F, Martinot S, Robin J, Allevard A, Vincent M, et al. Better preservation of endothelial function and decreased activation of the fetal renin-angiotensin pathway with the use of pulsatile flow during experimental fetal bypass. J Thorac Cardiovasc Surg. 2000;4:770-7.

20. Morales-Rosello J, Khalil A, Morlando M, Papageorghiou A, Bhide A, Thilaganathan B. Changes in fetal Doppler indices as a marker of failure to reach growth potential at term. Ultrasound Obstet Gynecol. 2014;43:303-10. 